\title{
Taxonomic evaluation of selected Ganoderma species and data base sequence validation
}

\author{
Suldbold Jargalmaa $^{1}{ }^{2}$, John A Eimes ${ }^{2}{ }^{2}$, Myung Soo Park ${ }^{1}$, Jae Young Park ${ }^{1}$, Seung-Yoon Oh ${ }^{1}$, Young Woon \\ Lim Corresp. 1 \\ ${ }^{1}$ School of Biological Sciences, Seoul National University, Seoul, South Korea \\ 2 University College, Sungkyunkwan University, Suwon, South Korea \\ Corresponding Author: Young Woon Lim \\ Email address: ywlim@snu.ac.kr
}

Species in the genus Ganoderma include several ecologically important and pathogenic fungal species whose medicinal and economic value is substantial. Due to the highly similar morphological features within the Ganoderma, identification of species has relied heavily on DNA sequencing using BLAST searches, which are only reliable if the GenBank submissions are accurately labeled. In this study, we examined 113 specimens collected from 1969-2016 from various regions in Korea using morphological features and multigene analysis (internal transcribed spacer, translation elongation factor 1- $\alpha$, and the second largest subunit of RNA polymerase II). These specimens were identified as four Ganoderma species: G. sichuanense, G. cf. adspersum, G. cf. applanatum, and G. cf. gibbosum. With the exception of $\mathrm{G}$. sichuanense, these species were difficult to distinguish based solely on morphological features. However, phylogenetic analysis at three different loci yielded concordant phylogenetic information, and supported the four species distinctions with high bootstrap support. A survey of over 600 Ganoderma sequences available on GenBank revealed that $65 \%$ of sequences were either misidentified or ambiguously labeled. Here, we suggest corrected annotations for GenBank sequences based on our phylogenetic validation and provide updated global distribution patterns for these Ganoderma species. 
1 Taxonomic evaluation of selected Ganoderma species and data base sequence validation

2

3 Running title: Taxonomy of the genus Ganoderma

4

5

6 Suldbold Jargalmaa ${ }^{1}$, John A. Eimes ${ }^{2}$, Myung Soo Park ${ }^{1}$, Jae Young Park ${ }^{1}$, Seung-Yoon Oh${ }^{1}$,

7 Young Woon $\operatorname{Lim}^{1 *}$

8

9

$10{ }^{1}$ School of Biological Sciences, Seoul National University, Seoul, South Korea

11 2Sungkyunkwan University, University College, Suwon, South Korea

12

13

14

15

16

17 *Corresponding author:

18 Y.W. Lim

19 E-mail address: ywlim@snu.ac.kr

20 Telephone: +82-2-880-6708; Fax: +82-2-871-5191 
21 Abstract

22 Species in the genus Ganoderma include several ecologically important and pathogenic fungal 23 species whose medicinal and economic value is substantial. Due to the highly similar 24 morphological features within the Ganoderma, identification of species has relied heavily on DNA 25 sequencing using BLAST searches, which are only reliable if the GenBank submissions are 26 accurately labeled. In this study, we examined 113 specimens collected from 1969-2016 from 27 various regions in Korea using morphological features and multigene analysis (internal transcribed 28 spacer, translation elongation factor $1-\alpha$, and the second largest subunit of RNA polymerase II).

29 These specimens were identified as four Ganoderma species: G. sichuanense, G. cf. adspersum, G. cf. applanatum, and G. cf. gibbosum. With the exception of G. sichuanense, these species were difficult to distinguish based solely on morphological features. However, phylogenetic analysis at three different loci yielded concordant phylogenetic information, and supported the four species distinctions with high bootstrap support. A survey of over 600 Ganoderma sequences available on GenBank revealed that $65 \%$ of sequences were either misidentified or ambiguously labeled. Here, we suggest corrected annotations for GenBank sequences based on our phylogenetic validation and provide updated global distribution patterns for these Ganoderma species. 
41 Fungal species in the genus Ganoderma Karst. (Ganodermataceae, Polyporales) include

42 ecologically important wood decay fungi of which some species are a well-known component of

traditional Asian medicine. Several species of Ganoderma have been reported to cause diseases associated with trees, including basal stem rot disease in oil palm caused by G. boninense (Susanto et al. 2005), and root-rot disease of Acacia trees caused by G. steyaertanum, G. mastoporum, and G. philippii (Glen et al. 2009). Despite the pathogenic nature of many Ganoderma species, many species, especially taxa identified as G. lucidum in Asia, are believed to possess medicinal characteristics, and have been used in traditional Asian medicine for millennia (Bishop et al. 2015). Ganoderma byproducts are increasingly being used in western medicine and related health industries, and the most recent estimate of the annual economic value of Ganoderma byproducts (calculated in 1995) was $~ 1.6$ billion USD (Chang and Buswell 1999); adjusting for inflation and economic growth, this annual economic value is likely several billion dollars in 2017. As our understanding of the biochemistry and genetics of Ganoderma biocompounds increases in tandem with increasing medicinal and economic demand for these byproducts, accurate identification of Ganoderma species is critical.

Ganoderma is likely a relatively young genus, originating in the tropics and recently expanding its range into temperate zones. The estimated number of Ganoderma species ranges from 250 to $>400$ (Moncalvo et al. 1995; Richter et al. 2015). The morphology of Ganoderma species is characterized by a crusty or shiny pileus surface and a two-layered basidiospore wall with a truncated apex. Due to the high similarity of basidiocarp features, it is likely that the Ganoderma is the most difficult genus to accurately identify to species of all polypores (Ryvarden and Gilbertson 1993). In fact, the Ganoderma have been described as being in a state of "taxonomic chaos" (Ryvarden 1991). Indeed, the wide range of estimates for the number of 
64 Ganoderma species exemplifies the ambiguity that permeates the taxonomy of this genus. Early

65 efforts to apply molecular markers toward the resolution of Ganoderma taxonomy used sequences

66 from internal transcribed spacer (ITS) and partial large subunit rDNA (Moncalvo et al. 1994, 1995,

67 Moncalvo 2000) and nearly complete small subunit rDNA sequences (Hong and Jung 2004,

68 Douanla-Meli and Langer 2009). More recently, Wang et al. (2012) assessed the identification of

69 European G. lucidum (a species originally described from England) and East Asia G. lucidum

70 using three loci and determined that the East Asia samples were genetically distinct from their

71 European counterparts and conspecific with G. sichuanense. Further complicating matters, Cao et

72 al. (2012) combined morphological characters with phylogenetic analyses of six loci and proposed naming East Asian G. lucidum as G. lingzhi; however, G. lingzhi is regarded as a synonym of $G$. sichuanense, the name proposed in 1983 (Wang et al. 2012). Following the rules of fungal nomenclature, the name G. sichuanense should be given preference over any synonyms (Richter et al. 2015).

The dramatic increase in available DNA sequences from molecular phylogenetic studies has helped resolve the taxonomy of numerous fungal groups. Sequences from the ITS have been particularly useful in the recent development of DNA barcoding of the fungi (Schoch et al. 2012), although other loci such as translation elongation factor 1- $\alpha($ tefl- $\alpha)$ and the second largest subunit of RNA polymerase II (rpb2) (Liu et al. 1999; Matheny et al. 2007) have been instrumental in resolving ambiguous evolutionary relationships among Ganoderma species. While molecular advances have in general led to improvements in phylogenetics and taxonomy, the relative ease and speed of DNA barcoding also has the potential to increase the confusion often associated with fungal taxonomy. Up to $20 \%$ of designated sequences in public databases may be erroneous because of improper species identification (Bridge et al. 2003; Vilgalys 2003; Nilsson et al. 2006). 
87 This problem is acute within the genus Ganoderma due to the absence of reliable morphological

88

89

90

91

92

93

94

95

96

97

100

101

102

103

104

105

106

107

108 characteristics, a high rate of synonymous classification, and incorrect taxonomic assignments in public data bases. The combination of morphology and molecular analysis (ideally multi-locus) can resolve the issues associated with this growing problem of misidentified sequence in public databases (Jung et al. 2014).

Sequencing costs have recently fallen precipitously as has the speed and ease with which specimens can be identified via sequencing. As a result, an increasing number of non-specialists, including edible mushroom cultivators as well as collectors and re-sellers of medicinal fungi, have relied on commercial sequencing companies to identify specimens. These identifications are often made using BLAST searches, which are only reliable if the GenBank submissions are accurately labeled. Thus, a re-evaluation of Ganoderma species that are endemic to Korea is needed and the accuracy of sequence data bases such as GenBank should be investigated.

In Korea, the first report of Ganoderma lucidum (reported as Fomes japonicus) was 1934 (Murata 1934). The classification system of Ganoderma proposed by Imazeki (1952) divided the Ganoderma into two subgenera, with laccate species (including G. lucidum) in the subgenus Ganoderma and non-laccate species (including E. applanatum) in the subgenus Elfvingia. To date, five Ganoderma species, G. applanatum, G. lipsiense, G. lucidum G. neojaponicum, and G. tsugae, have been recorded in Korea (Kaburagi 1940; Lee 1981; Kang 1991; Kwon et al. 2016). G. lipsiense, however, is synonymous with G. applanatum (Moncalvo and Ryvarden 1997), therefore only four Ganoderma species were known in Korea. Importantly, most Korean Ganoderma species were reported solely on basidiocarp morphology without detailed descriptions or molecular data. 
110 morphology and molecular analysis and to correct species misidentifications in GenBank. In

111 addition, we provide updated global distribution patterns of these four Ganoderma species using

112 newly validated GenBank sequences.

114 Materials and methods

\section{Sample collection and morphological analysis.}

116 Specimens were collected from 1969-2016 from various regions in Korea and stored at the Seoul

117 National University Fungus Collection (SFC) and Korea Mushroom Resource Bank (KMRB).

118 These specimens were initially identified as G. lucidum, G. neojaponicum, and G. applanatum

119 (Table S1). Because the complex characteristics of the basidiocarps of Ganoderma have 120 contributed to confusion in the taxonomy of this genus, we sorted specimens using macro- and 121 micro-morphological observations (Gilbertson and Ryvarden 1986; Cao et al. 2012). Initially, 122 three morphological features were observed for 113 specimens: shape of basidiocarp, pore number 123 per mm at hymenophore, and basidiospore size. Pore number was calculated as the mean of five 1 $124 \mathrm{~mm}$ transects across hymenium. In order to observe basidiospores, slide preparations mounted in $1253 \% \mathrm{KOH}$ were made from dried tissue for each specimen and examined with a Nikon 80i light 126 microscope (Nikon, Tokyo, Japan). 
12929 recently collected Korean specimens were chosen for DNA sequencing (Table 1). Genomic 130 DNA was extracted using a modified CTAB extraction protocol (Rogers and Bendich 1994). The

131 ITS region, partial tefl- $\alpha$, and partial $r p b 2$ regions were amplified using the primers ITS1F/ITS4b

132 (Gardes and Bruns 1993), EF1-983F/EF1-2218R (Rehner and Buckley 2005), and fRPB2-

133 5F/bRPB2-7R2 (Liu et al. 1999; Matheny et al. 2007), respectively. PCRs were performed on a

134 C1000TM thermal cycler (Bio-Rad, Richmond, CA, USA) using AccuPower PCR premix

135 (Bioneer Co., Daejeon, Korea) according to the methods described in Park et al. (2013). PCR

136 products were electrophoresed through a 1\% agarose gel stained with EcoDye DNA staining

137 solution (SolGent Co., Daejeon, Korea) and purified using the Expin ${ }^{\mathrm{TM}}$ PCR Purification Kit

138 (GeneAll Biotechnology, Seoul, Korea) according to the manufacturer's instructions. DNA

139 sequencing was performed at Macrogen (Seoul, Korea) using an ABI3700 automated DNA

140 sequencer. Sequences obtained from specimens were proofread using chromatograms in MEGA

141 v. 6 (Tamura et al. 2013).

\section{Phylogenetic analysis}

Phylogenetic analysis was carried out in two steps. First, phylogenetic trees using ITS, tefl- $\alpha$, and rpb2 sequences were constructed using only specimens of Korean Ganoderma species. Second,

146 we downloaded all Ganoderma sequences obtained from the search query "Ganoderma" in

147 GenBank. SFC amplicon sequences of ITS, tefl- $\alpha$, and rpb2 were aligned with Ganoderma 148 sequences downloaded from GenBank using the default settings of MAFFT v.7 (Katoh and 149 Standley 2013). Maximum likelihood (ML) trees were constructed with RAxML 8.0.2 (Stamatakis 
150 2014) using the GTRGAMMA model of evolution and 1,000 bootstrap replicates. Coriolopsis cf.

151 caperata was used as an outgroup for all three phylogenetic trees (Binder et al. 2013).

152

153 Validation and distribution of GenBank Ganoderma sequences

154 We used BLAST to validate Ganoderma sequences in GenBank. GenBank sequences for $G$. 155 sichuanense were available for all three loci (ITS, tef1- $\alpha$, and $r p b 2)$; however, there were 156 insufficient sequences for the other species at the tefl- $\alpha$ and $r p b 2$ loci. Thus, our validation for

157 these species is limited to the ITS locus. ITS sequences from each Korean species were used for 158 the BLAST searches and sequences were downloaded based on similarity and coverage. We 159 downloaded all sequences that had a similarity of $>90 \%$ at the ITS. We excluded short sequences 160 by removing those that had coverage of $<50 \%$. Neighbor Joining $(\mathrm{NJ})$ analyses were performed 161 using these sequences to determine the correct sequence identity for each Ganoderma species. NJ 162 trees were constructed with MEGA v. 6, using the Kimura 2-parameter model and 1,000 bootstrap 163 replicates. All work with GenBank was performed on September 20, 2016. of the global distribution. Distribution information of each species was extracted from published papers and direct GenBank submissions.

\section{Results}


170 All 113 specimens identified as Ganoderma were used in the preliminary portion of this study.

171 These samples were reexamined based on distinguishable morphological characters. First, 172 specimens with laccate basidiocarps and long stipes were distinguished from other specimens with 173 non-laccate basidiocarps. Laccate specimens initially identified as G. lucidum, G. lingzhi and G. 174 neojaponicum were identified as G. sichuanense using molecular analysis based on ITS, tef-1, and 175 rpb2. Basidiocarps were reniform to circular with long subcylindrical stipe (Fig. 1a, b), had 176 circular or angular pores that were at a density of 5-6 per mm (Fig. 2a), and basidiospore size was 177 (9.7) 10.4-11.1 (12.2) ×(6.4) 6.6-6.9 (7.4) $\mu \mathrm{m}$ (Fig. 2b).

While all non-laccate specimens were similar to G. applanatum, they could be separated 179 into three different morphology types. Type A specimens had sessile basidiocarps, and were attached directly to the tree at its base with no stipe (Fig. 1c, d). Pore number was 3-4 per mm (Fig. 2a) and basidiospore size range was (7.8) 8.3-10.6 (11.3) × (5.1) 5.4-7.4 (7.8) $\mu \mathrm{m}$ (Fig. 2b). Type B specimens had sessile basidiocarps with no stipes (Fig. 1e, f), a pore number range of 5-7 per mm (Fig. 2a), and basidiospore size of (8.0) 8.1-8.5 (8.9) × (5.3) 5.4-5.8 (6.3) $\mu \mathrm{m}$ (Fig. 2b). The basidiocarps of type $\mathrm{C}$ specimens were attached to broad-leaved tree stumps with short stipes (Fig. 1g, h), a pore number range of 4-5 per mm (Fig. 2a), and basidiospore size of (7.7) 8.5-9.2 186 $(9.4) \times(4.9) 5.6-6.0(6.5) \mu \mathrm{m}($ Fig. 2b). The ITS region was successfully amplified and sequenced for 29 representative specimens. However, sequences for the tefl- $\alpha$ and $r p b 2$ regions were obtained from fewer specimens (Table 1). Phylogenetic relationships inferred from the ITS, tefl- $\alpha$, and $r p b 2$ ML trees exhibited a clear distinction between the four species (Fig. 3). This phylogeny supported the identification of the

191 laccate specimens as $G$. sichuanense. The three morphological types of non-laccate specimens 192 clearly separated into three species. We re-named type A Ganoderma cf. adspersum, type B 
193 Ganoderma cf. applanatum, and type C Ganoderma cf. gibbosum because type specimens were

194 not included in this study. Within the ITS, tef1- $\alpha$, and rpb2 phylogenies, G. cf. adspersum formed

195 a supported clade with G. cf. gibbosum. G. cf. applanatum formed a distinct cluster with these two

196 species to the exclusion of G. sichuanense (Fig. 3).

197

198

\section{GenBank sequence validation and distribution of four Ganoderma species}

199

200

201

202

203

204

205

206

207

208

209

210

211

212

213

214

Using BLAST searches and phylogenetic analysis, we were able to validate the sequences of four Ganoderma species in GenBank. Of 249 ITS sequences that were identified by this study as $G$. sichuanense, 239 were annotated in GenBank as G. sichuanense, G. lucidum or G. lingzhi, seven were undetermined (Ganoderma sp.) and three were mislabeled (two as G. tsugae and one as G. luteomarginatum). One GenBank sequence submission was incorrectly identified as G. lingzhi and three were misidentified as G. sichuanense. 111 GenBank submissions that were initially annotated in GenBank as G. lucidum were neither Asian (G. sichuanense) or European $(G$. lucidum) Ganoderma species. Thus, of 354 GenBank submissions labeled as G. sichuanense or its synonyms, 115 (32\%) were found to belong to different species (Fig. 4, Table S2).

88 ITS sequences were defined by this study as $G$. cf. adspersum. Sixteen $G$. cf. adspersum sequences were mislabeled in GenBank as either G. applanatum (4) or G. australe (12). Seven were ambiguously labeled (as Ganoderma sp.). One sequence was labeled "Ganoderma clone" and four were misidentified as non-Ganoderma genera. In addition, we found four GenBank sequences that were erroneously labeled as G. adspersum (Fig. 4, Table S2). 
215 mislabeled Ganoderma species (three as G. adspersum and one as G. oregonense) and seven were 216 ambiguously labeled (e.g. Ganoderma sp.). Of 70 GenBank sequence submissions originally 217 labeled as G. applanatum or its synonym G. lipsiense, 24 (34\%) were found to belong to different 218 species (Fig. 4, Table S2).

We identified 34 GenBank sequences as G. cf. gibbosum. 17 GenBank sequences were correctly annotated, while 14 were initially misidentified as other Ganoderma species (seven as G. applanatum, five as G. australe, one as G. fulvellum, and one as G. lucidum). Three G. cf. gibbosum sequences were ambiguously labeled as "Ganoderma sp.”. 14 of 31 (45\%) GenBank sequence submissions that were initially identified as G. gibbosum were found to be different species (Fig. 4).

Based on the corrected database, we generated a distribution map for each species $(G$. sichuanense, G. cf. adspersum, G. cf. applanatum, and G. cf. gibbosum) (Fig. S1). G. sichuanense was distributed throughout Asia (e.g. China, Japan, Korea, Bangladesh, Malaysia, and Nepal); although nearly $70 \%$ of the G. sichuanense sequences were described from China. While some sequences were identified as from Poland and Italy, their specimen information lacked confirmation due to directly deposition without publication. Most G. cf. adspersum sequences were from European countries (Italy, Germany, Poland, United Kingdom, Austria, Finland, and France), while a small number of sequences were from Asia (India, Japan, and Korea). G. cf. applanatum sequences had a global distribution (USA, Canada, Lithuania, Hungary, Germany, Poland, Korea, and Antarctica). G. cf. gibbosum sequences were mostly limited to Asia (Korea, China, Japan, and 


\section{Discussion}

238 Morphological and molecular analysis of Korean Ganoderma specimens collected during the last

239 fifty years indicated that there are four Ganoderma species in Korea. Among the four previously

240 described Ganoderma species, G. neojaponicum and G. tsugae were not found in this study.

241 Although one specimen that was identified as G. neojaponicum was shown to be G. sichuanense,

242 further study is needed to establish whether G. neojaponicum and G. tsugae exist in Korea.

et al. (2016) suggested that G. lucidum cultivated in Korea (locally known as Yeongji) was actually

G. lingzhi, although we argue for renaming all G. lingzhi as G. sichuanense (see above). G.

sichuanense is easily distinguished from the other three Korean Ganoderma species by differences

in surface texture of the pileus and basidiospore size (Moncalvo and Ryvarden 1997; Tham 1998).

Laccate pileus with longer stipe and larger basidiospores than other Asian Ganoderma species are typical characters of G. sichuanense (Wang et al. 2012). Furthermore, phylogenetic analysis confirmed that the Korean G. sichuanense sequences used in this study were nearly identical to the epitype for G. sichuanense (KC662402) (Yao et al. 2013). of these species, although basidiocarp morphology has been suggested to differentiate these species. Basidiocarps of $G$. cf. adspersum (40-100 mm) are usually thicker than those of $G$. cf. applanatum $(20-60 \mathrm{~mm})$ at the base. In addition, the undersides of the basidiocarps of $G$. cf. adspersum have a decurrent attachment, whereas those of $G$. cf. applanatum tend to emerge 
259 2003). In a radial section of the hymenophore of the older parts of the fruiting body, those of $G$.

260 cf. adspersum remain empty but the pores of $G$. cf. applanatum become filled with a white

261 mycelium (Breitenbach and Kränzlin 1986). G. cf. adspersum is distinguished from G. cf.

262 applanatum by having larger basidiospores (Steyaert 1972; Ryvarden and Gilbertson 1993). G. cf.

263 gibbosum is distinguished from G. cf. applanatum by the presence of the stipe (Blume and Nees

264 von Esenbeck 1826). It has been suggested, however, that stipe formation may be an adaptive

265 feature because individuals of the G. applanatum-australes complex can develop a stipe in the

266 tropics and stipe formation can be induced in the laboratory in strains of G. applanatum-australes

267 complex species (Moncalvo and Ryvarden 1997). Nevertheless, Korean specimens in our study

268 were distinguished by three characteristics: The presence of the stipe discriminated G. cf.

269 gibbosum from G. cf. adspersum and G. cf. applanatum (Fig. 1) and larger basidiospore and pore

270 size discriminated G. cf. adspersum from G. cf. applanatum (Fig. 2).

271 Despite similar morphology, a multigene phylogenetic analysis showed that $G$. cf.

272 adspersum, G. cf. applanatum, and G. cf. gibbosum, are distinct species (Fig. 3) corresponding to

273 clades 2, 1, and 5, respectively, of the Ganoderma global phylogeny that was constructed by

274 Moncalvo and Buchanan (2008). Our results also support previous phylogenetic reconstructions

275 where G. cf. adspersum and G. cf. applanatum were clearly separated by rDNA analysis and

276 further distinguished by species specific PCR primers (Gottlieb et al. 2000; Guglielmo et al. 2008).

277 While G. cf. adspersum and G. cf. gibbosum formed a supported clade separate from $G$.

278 sichuanense, G. cf. adspersum and G. cf. gibbosum appear to be closely related with $100 \%$

279 bootstrap support in tef1- $\alpha$ and $r p b 2$ phylogenetic trees (Fig. 3). 
282 to be misidentified than other loci due to their over-representation among phylogenetic markers.

283 Open DNA databases (DB) such as GenBank are an important tool for species identification. In

284 medicinal fungi, such as Ganoderma species, the need for satisfactory taxonomic sampling and

285 accurate identification in DBs is critical. Among the four species, the highest number of ITS

286 sequences listed on GenBank was those of G. sichuanense (Fig. 4) and the unusually high number

287 of G. sichuanense sequences found on GenBank is likely due to the economic and medicinal

288 importance of the species. In order to minimize confusion and misidentification in future studies,

289 we strongly recommend that the names G. lucidum and G. lingzhi be avoided and all new

290 submissions of this species be labeled G. sichuanense. The distribution of G. sichuanense appears

291 to be limited to Asia, with specimens reported from China, Korea, Japan, Bangladesh, Malaysia, 292 and Nepal (Fig. S1).

Our study shows that G. cf. adspersum sequences in GenBank were commonly considered a synonym of G. australe by Ryvarden (1976) and Ryvarden and Gilbertson (1993); however, Smith and Sivasithamparam (2000), using ITS sequence data, argued that G. adspersum and G. australe are two distinct species. G. adspersum was commonly reported from Europe, where type specimens were collected (Moncalvo and Ryvarden 1997; Smith and Sivasithamparam 2000). Our analysis confirmed that G. cf. adspersum occurs in Europe, but is distributed in Asia and North America as well (Fig. S1). Erroneously annotated sequences were also common among G. cf. applanatum GenBank submissions. $34 \%$ of sequences that were initially annotated as $G$. cf. applanatum were shown to be other species while just $54 \%$ of authentic $G$. cf. applanatum 303 sequences were initially annotated as such in GenBank. A total of 13 sequences that were labeled as G. lipsiense in GenBank were included in the G. cf. applanatum clade because G. lipsiense is 
305 synonymous with $G$. cf. applanatum (Moncalvo and Ryvarden 1997). Our analysis confirmed that 306 G. cf. applanatum has a global distribution (Moncalvo and Ryvarden 1997) with sequences 307 reported from Europe, Asia and North America (Fig. S1). Nearly half of all GenBank sequences 308 annotated as $G$. cf. gibbosum were misidentified and the same proportion of authentic $G$. cf. 309 gibbosum sequences were initially annotated as different species. G. cf. gibbosum has a primarily 310 Asian distribution, and the ecto-type was initially reported from Java, Indonesia (Blume and Nees 311 von Esenbeck 1826), although scattered samples were reported from Eastern Europe.

313 GenBank, it became apparent that many Ganoderma reference sequences were misidentified. In 314 this study, we identified incorrectly labeled sequences on GenBank and constructed new 315 phylogenies with reference sequences that were correctly assigned to specific taxa. This study will 316 provide a framework for future efforts to replace inaccurate public information with reliable 317 taxonomic assignments. We strongly encourage the authors of previously submitted specimens 318 that have been shown to be misidentified or use inappropriate species names (i.e. lucidum and 319 lingzhi) to correct these submissions on GenBank. This improvement is vital not only for fungal taxonomists, but given the diverse ecological, medicinal, and economic impacts of Ganoderma species, this project will be of value to researchers across multiple disciplines.

\section{Acknowledgements}

324 We greatly appreciate two anonymous reviewers for their detailed and kind comments. 
325

326

327

328

329

330

331

332

333

334

335

336

337

338

339

340

341

342

343

\section{References}

Binder M, Justo A, Riley R, Salamov A, Lopez-Giraldez F, Sjökvist E, Copeland A, Foster B, Sun H, Larsson E, Larsson KH, Townsend J, Grigoriev IV, Hibbett DS (2013) Phylogenetic and phylogenomic overview of the Polyporales. Mycologia 105:1350-1373

Bishop KS, Kao CH, Xu Y, Clucina MP, Paterson RR, Ferguson LR (2015) From 2000 years of Ganoderma lucidum to recent developments in nutraceuticals. Phytochemistry 114:56-65

Blume C, Nees von Esenbeck TFL (1826) Fungi javanici, editi conjunctis studis et opera. Nova Nova Acta Caesar Leop Carol Halle 13:9-22

Breitenbach J, Kränzlin F (1986) Fungi of Switzerland. Verlag Mykologia, Lucerne

Bridge PD, Roberts PJ, Spooner BM, Panchal G (2003) On the unreliability of published DNA sequences. New Phytol 160:43-48

Cao Y, Wu SH, Dai YC (2012) Species clarification of the prize medicinal Ganoderma mushroom “Lingzhi”. Fungal Divers 56:49-62

Chang ST, Buswell JA (1999) Ganoderma lucidum (Curt.:Fr) P. Karst. (Aphyllophoromycetideae) - A mushrooming medicinal mushroom. Int J Med Mushrooms 1:139-146

Douanla-Meli C, Langer E (2009) Ganoderma carocalcareus sp. nov., with crumblyfriable context parasite to saprobe on Anthocleista nobilis and its phylogenetic relationship in G. resinaceum group. Mycol Prog 8:145-155 
344 Gardes M, Bruns TD (1993) ITS primers with enhanced specificity for basidiomycetes-application

345 to the identification of mycorrhizae and rusts. Mol Ecol 2:113-118

346 Gilbertson RL, Ryvarden L (1986) North American polypores. Fungiflora, Oslo

347 Glen M, Bougher NL, Francis AA, Nigg SQ, Lee SS, Irianto R, Barry KM, Beadle CL, Mohammed

CL (2009) Ganoderma and Amauroderma species associated with root-rot disease of Acacia mangium plantation trees in Indonesia and Malaysia. Australas Plant Pathol 38:345-356

350

351

352

353

354

355

356

357

358

359

360

361

362

363

Gottlieb AM, Ferrer E, Wright JE (2000) rDNA analyses as an aid to taxonomy of species of Ganoderma. Mycol Res 104:1033-1045

Guglielmo F, Gonthier P, Garbelotto M, Nicolotti G (2008) A PCR-based method for the identification of important wood rotting fungal taxa within Ganoderma, Inonotus s.l. and Phellinus s.1.. FEMS Microbiol Lett 282:228-237

Hong SG, Jung HS (2004) Phylogenetic analysis of Ganoderma based on nearly complete mitochondrial small-subunit ribosomal DNA sequences. Mycologia 96:742-755

Imazeki R (1952) A contribution to the fungus flora of Dutch New Guinea. Bull Govt For Exp St Tokyo 57:87-128

Jung PE, Fong JJ, Park MS, Oh SY, Kim C, Lim YW (2014) Sequence validation for the identification of the white-rot fungi Bjerkandera in public sequence databases. J Microbiol Biotechnol 24:1301-1307

Kaburagi Y (1940) Korean and Manchurian practical manual of forest. Korea Forest Experiment Station. Yokendo, Tokyo, pp 339-367 
364 Kang ID (1991) The study of higher fungal flora in Pusan area. Dissertation, Kyungsung $365 \quad$ University

366 Katoh K, Standley DM (2013) MAFFT multiple sequence alignment software version 7:

367 improvements in performance and usability. Mol Biol Evol 30:772-780

Kwon OC, Park YJ, Kim HI, Kong WS, Cho JH, Lee CS (2016) Taxonomic position and species identity of the cultivated Yeongji 'Ganoderma lucidum' in Korea. Mycobiology 44:1-6

Lee JY (1981) Taxonomical studies on Korean higher fungi for the publication of colored illustrations. Kor J Mycol 9:77-91

Liu YL, Whelen S, Hall BD (1999) Phylogenetic relationships among ascomycetes: evidence from an RNA polymerase II subunit. Mol Biol Evol 16:1799-1808

Matheny PB, Wang Z, Binder M, Curtis JM, Lim YW, Nilsson RH, Hughes KW, Petersen RH, Hofstetter V, Ammirati JF, Schoch C, Langer GE, McLaughlin DJ,Wilson AW, Crane PE, Frøslev T, Ge ZW, Kerrigan RW, Slot JC, Vellinga EC, Liang ZL, Aime MC, Baroni TJ, Fischer M, Hosaka K, Matsuura K, Seidl MT, Vaura J, Hibbett DS (2007) Contributions of rpb2 and tef1 to the phylogeny of mushrooms and allies (Basidiomycota, Fungi). Mol Phylogenet Evol 43:430-451

Murata MM (1934) Plant list of Korea and Manchuria. Tokyo

Moncalvo JM (2000). Systematics of Ganoderma. In: Flood J, Bridge PD, Holderness M (eds) Ganoderma diseases of perennial crops. CABI Bioscience, Egham, pp 23-45. 
383 Moncalvo JM, Buchanan PK (2008) Molecular evidence for long distance dispersal across the 384 Southern Hemisphere in the Ganoderma applanatum-australe species complex 385 (Basidiomycota). Mycol Res 112:425-436

386 Moncalvo JM, Ryvarden L (1997) A nomenclatural study of the Ganodermataceae Donk. $387 \quad$ Fungiflora, Oslo

388 Moncalvo JM, Wang HF, Wang HH, Hseu RS (1994) The use of ribosomal DNA sequence data 389 for species identification and phylogeny in the Ganodermataceae. In: Buchanan PK, Hseu RS, 390 Moncalvo JM (ed) Ganoderma: systematics, phytopathology and pharmacology. International 391 Mycological Congress, Vancouver, pp 31-44

392

Moncalvo JM, Wang HH, Hseu RS (1995) Phylogenetic relationships in Ganoderma inferred from the internal transcribed spacers and 25S ribosomal DNA sequences. Mycologia 87:223-238

Nilsson RH, Ryberg M, Kristiansson E, Abarenkov K, Larsson K-H, Kõljalg U (2006) Taxonomic reliability of DNA sequences in public sequence databases: a fungal perspective. PLoS ONE $1: \mathrm{e} 59$

Park MS, Fong JJ, Lee H, Oh SY, Jung PE, Min YJ, Seok SJ, Lim YW (2013) Delimitation of Russula subgenus Amoenula in Korea using three molecular markers. Mycobiology 41:191201

Rehner SA, Buckley E (2005) A Beauveria phylogeny inferred from nuclear ITS and EF1- $\alpha$ sequences: evidence for cryptic diversification and links to Cordyceps teleomorphs. Mycologia 97:84-98 
403 Richter C, Wittstein K, Kirk PM, Stadler M (2015) An assessment of the taxonomy and 404 chemotaxonomy of Ganoderma. Fungal Divers 71:1-15

405 Rogers SO, Bendich AJ (1994). Extraction of total cellular DNA from plants, algae and fungi. In: 406 Gelvin SB, Schilperoort RA (ed) Plant molecular biology manual, Kluwer Academic, 407 Dordrecht, pp 1-8

408 Ryvarden L (1991) Genera of polypores, nomenclature and taxonomy. Fungiflora, Oslo

409 Ryvarden L, Gilbertson RL (1993) European polypores-Abortiporus-Lindtneria. Vol 1. Syn Fung $410 \quad 13: 1-387$

411 Schoch CL, Seifert K, Huhndorf S, Robert V, Spouge JL, Levesque CA, Chen W, Fungal 412 Barcoding Consortium (2012) Nuclear ribosomal internal transcribed spacer (ITS) region as a universal DNA barcode marker for fungi. Proc Natl Acad Sci USA 109:6241-6246

414 415 416 417 418 419 420 421

Schwarze FWMR and Ferner D (2003) Ganoderma on trees - differentiation of species and studies of invasiveness. Arboric J 27:59-77

Smith BJ, Sivasithamparam K (2000) Internal transcribed spacer ribosomal DNA sequence of five species of Ganoderma from Australia. Mycol Res 104:943-951

Stamatakis A (2014) RAxML version 8: A tool for phylogenetic analysis and post-analysis of large phylogenies. Bioinformatics 30:1312-1313

Steyaert RL (1972) Species of Ganoderma and related genera mainly of the Bogor and Leiden herbaria. Persoonia 7:55-118 
422 Susanto A, Sudharto PS, Purba RY (2005) Enhancing biological control of basal stem rot disease

423 (Ganoderma boninense) in oil palm plantations. Mycopathologia 159:153-157

424 Tamura K, Stecher G, Peterson D, Filipski A, Kumar S (2013) MEGA6: molecular evolutionary 425 genetics analysis version 6.0. Mol Biol Evol 30:2725-2729

426 Tham LX (1998) A phylogenetic hypothesis of the Ganodermataceae based on possible mode of 427 basidiospores evolution. Mycotaxon 69:1-12

428 Vilgalys R (2003) Taxonomic misidentification in public DNA databases. New Phytol 160:4-5

429 Wang XC, Xi RJ, Li Y, Wang DM, Yao YJ (2012) The Species identity of the widely cultivated 430 Ganoderma, ‘G. lucidum’ (Ling-zhi), in China. PLoS ONE 7: e40857

431 Yao YJ, Wang XC, Wang B (2013) Epitypification of Ganoderma sichuanense J.D. Zhao \& X.Q.

432 Zhang (Ganodermataceae). Taxon 62:1025-1031

433

434

435

436

437

438

439

440

441 

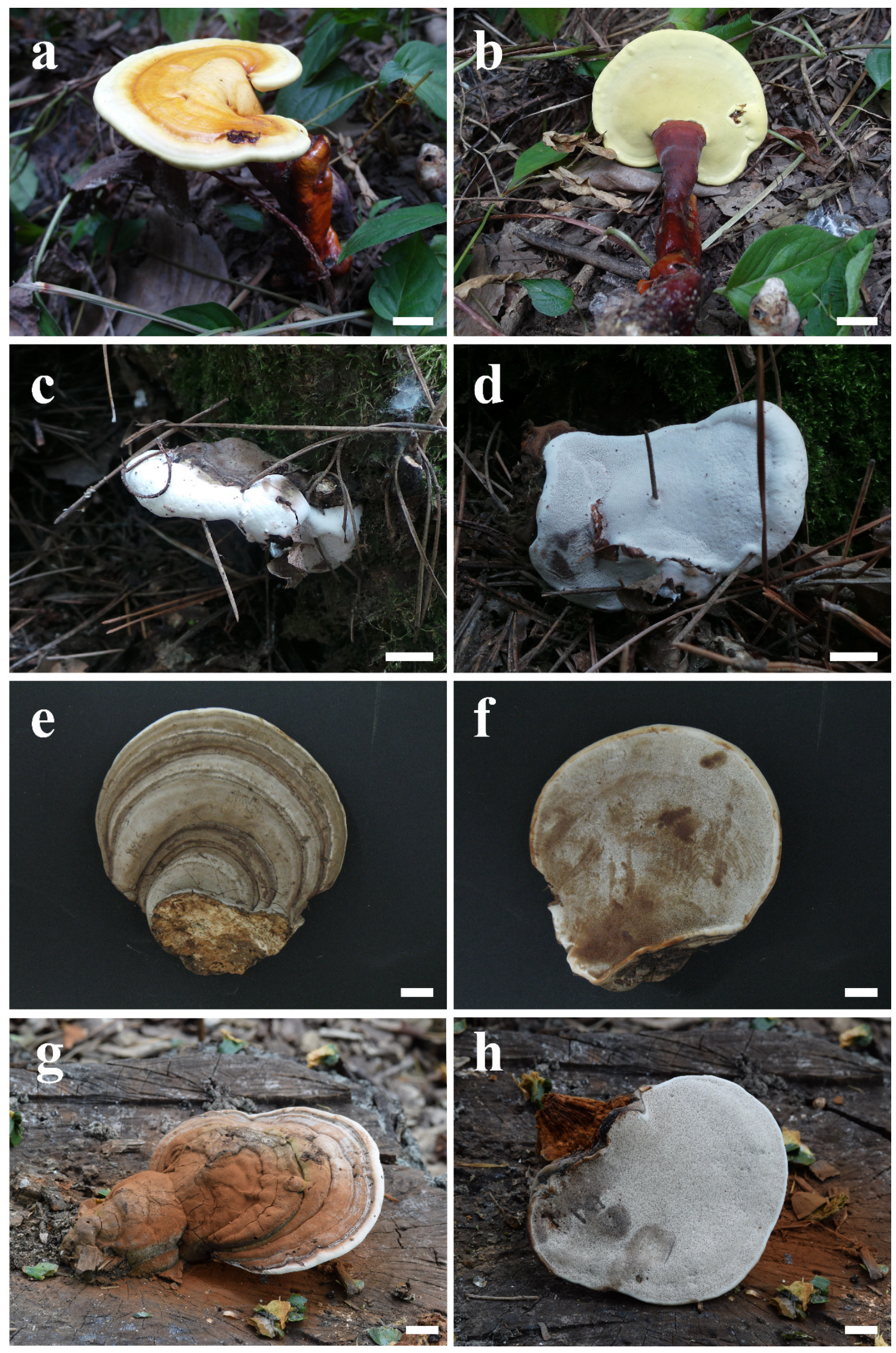
446 Fig. 1 Basidiocarps of Ganoderma; G. sichuanense (a-b), G. cf. adspersum (c-d), G. cf. applanatum (e-f), and $G$. cf. gibbosum $(\mathrm{g}-\mathrm{h})$. Scale bars: $\mathrm{a}-\mathrm{h}=1 \mathrm{~cm}$.

a

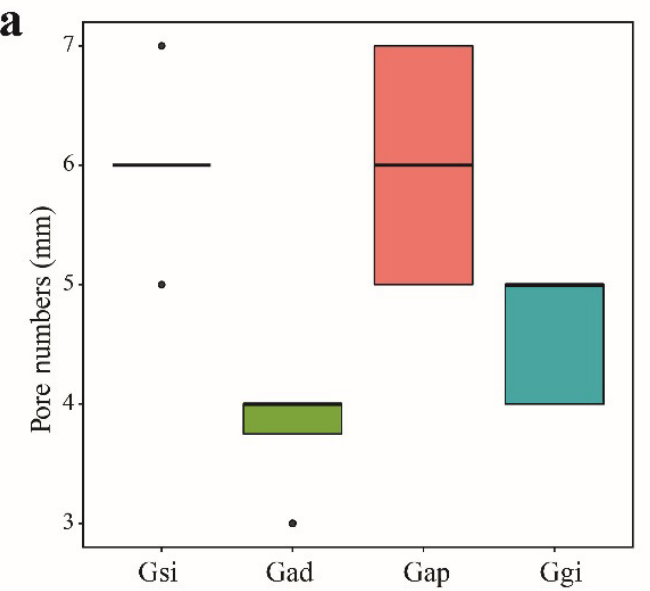

b

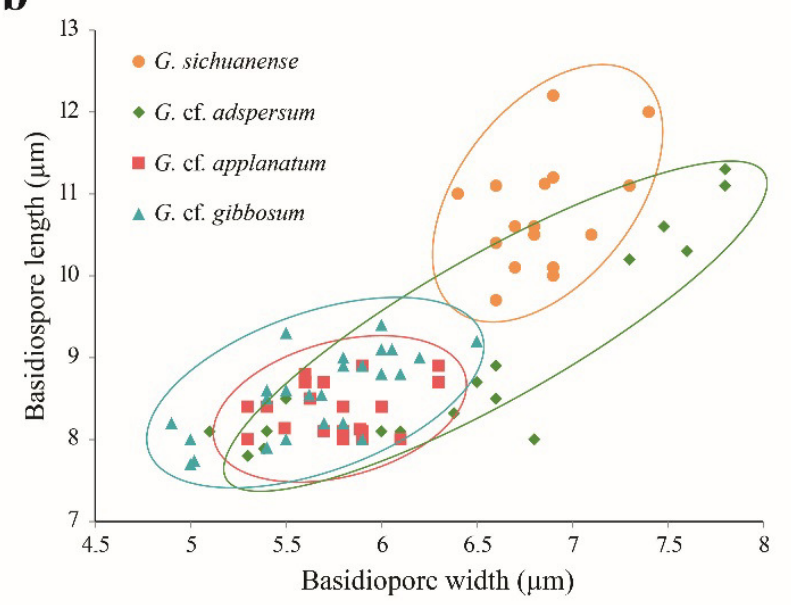

448

449

450

451

452

453

454

455

456

457

458

459

460

461

462

463

464

Fig. 2 a: box plot representing pore number per mm of four Ganoderma species: G. sichuanense (Gsi), G. cf. adspersum (Gad), G. cf. applanatum (Gap), and G. cf. gibbosum (Ggi). Boxes represent the interquartile range between first quartile and third quartile. Bold line in the box is the median and filled circles represent individual outlying data points. b: scatter plot of basidiospore size among the four species $(\mathrm{mm})$. Four samples were observed for each species.

4

5

6

57


465 


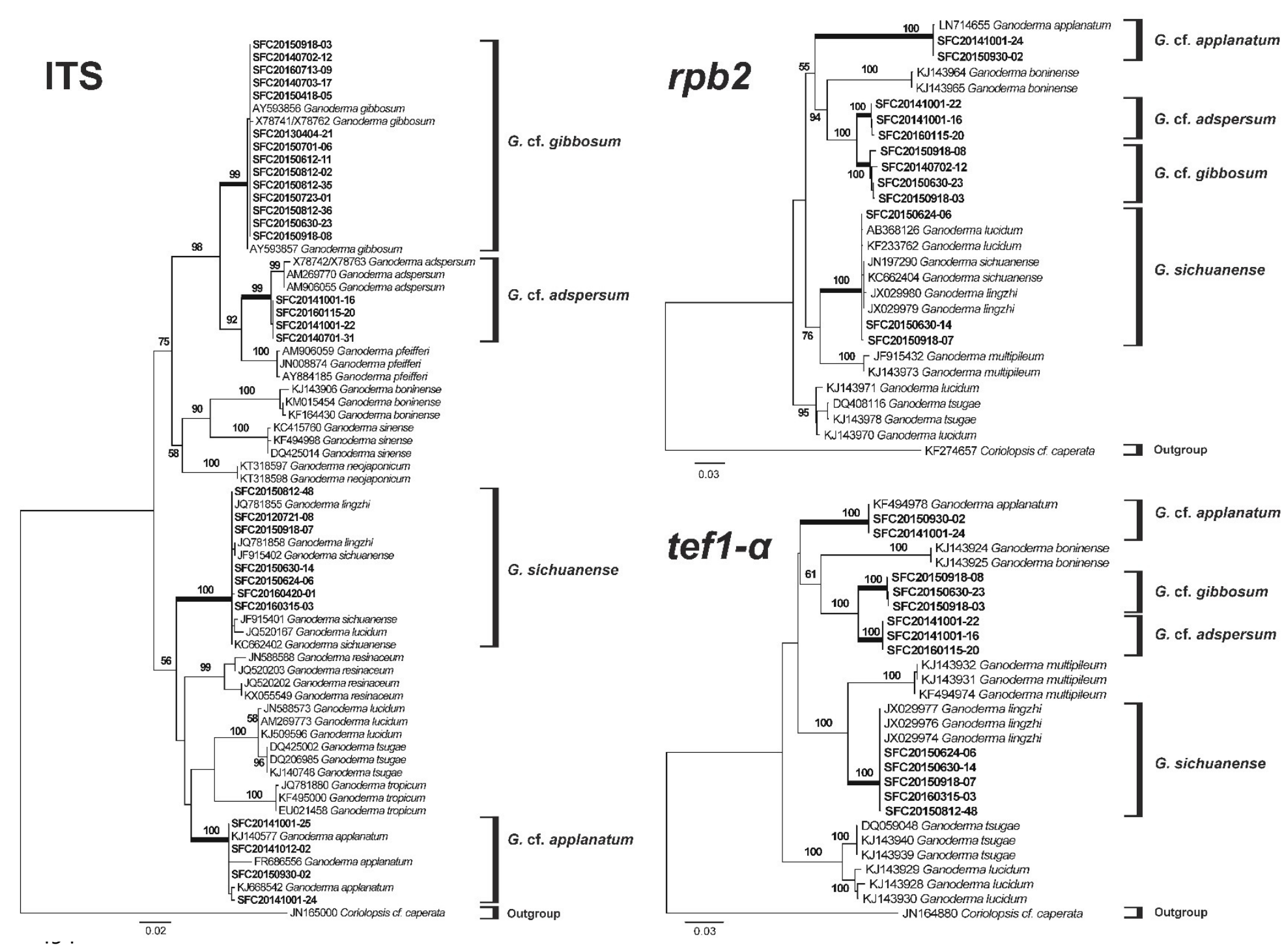

Fig. 3 Phylogenetic tree for Ganoderma and related species based on a maximum likelihood (ML) analysis of the internal transcribed spacer (ITS), the second largest subunit of RNA polymerase II (rpb2), and translation elongation factor $1-\alpha$ (tefl- $\alpha)$. ML trees were constructed with RAxML 8.0.2 using the GTRGAMMA model of evolution and 1,000 bootstrap replicates. Bootstrap scores of $>50$ are presented at the nodes. Branches that involved SFC sequences are in bold. The scale bar indicates the number of nucleotide substitutions per site. 


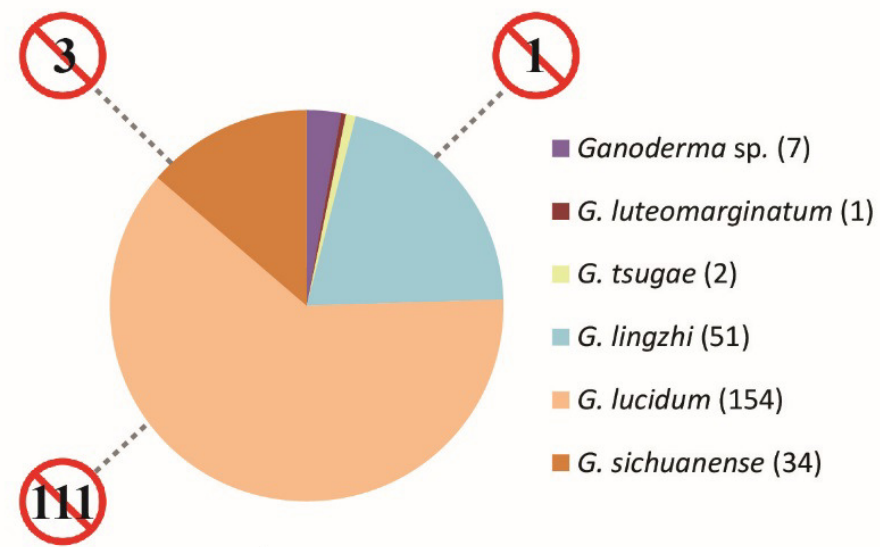

G. sichuanense

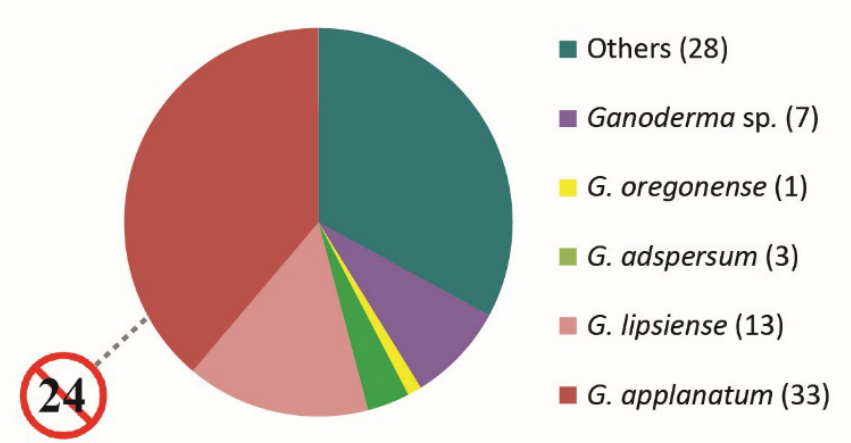

G. cf. applanatum

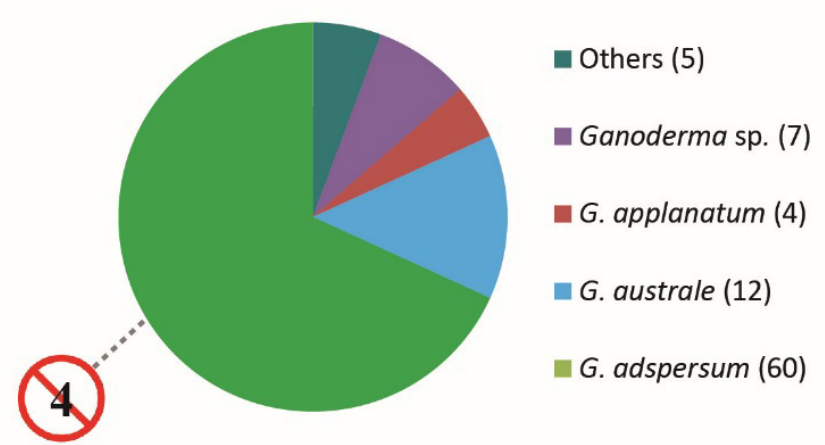

G. cf. adspersum

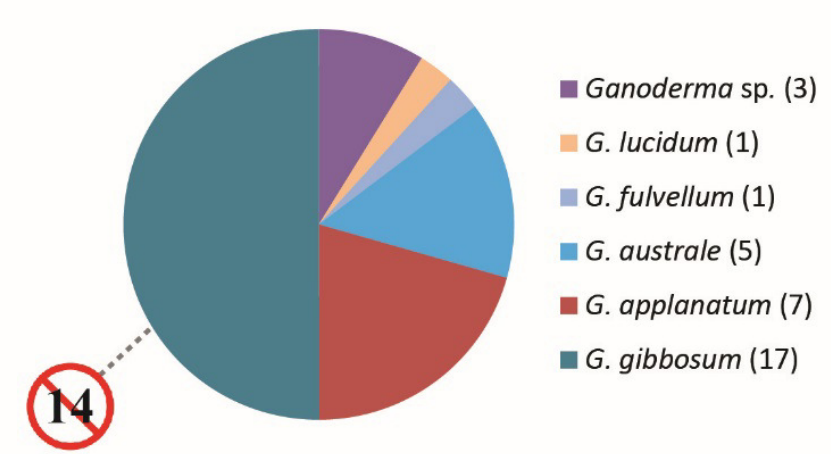

G. cf. gibbosum

Fig. 4 Incorrect names applied to Ganoderma sequences in GenBank. Color-coded taxon identifiers indicate initial GenBank annotations (number of sequences are in parentheses); "other" indicates annotations labeled as "Ganoderma clone" or as non-Ganoderma genera. Numbers in barred circles represent GenBank submissions that were incorrectly identified as indicated species. G. lingzhi $=G$. 
Table 1 Representative Ganoderma specimens from the Seoul National University Fungus Collection (SFC) used in this study.

\begin{tabular}{|c|c|c|c|c|c|c|}
\hline \multirow{2}{*}{ Species } & \multirow{2}{*}{ Specimen No. } & \multicolumn{2}{|c|}{ Collection sites } & \multicolumn{3}{|c|}{ Accession number } \\
\hline & & Locality & Latitude / Longitude & ITS & $r p b 2$ & tef1- $\alpha$ \\
\hline \multirow[t]{7}{*}{ G. sichuanense } & SFC20120721-08 & Gimpo-si, Gyeonggi-do & $37^{\circ} 36^{\prime} 08.43^{\prime \prime} \mathrm{N} / 126^{\circ} 46^{\prime} 33.51^{\prime \prime} \mathrm{E}$ & KY364244 & & \\
\hline & SFC20150624-06 & Pohang-si, Gyeongsangbuk-do & $36^{\circ} 04^{\prime} 20.02^{\prime \prime} \mathrm{N} / 129^{\circ} 12^{\prime} 36.56^{\prime \prime} \mathrm{E}$ & KY364245 & KY393267 & KY393279 \\
\hline & SFC20150630-14 & Jongno-gu, Seoul & $37^{\circ} 34^{\prime} 28.50^{\prime \prime} \mathrm{N} / 126^{\circ} 59^{\prime} 38.92^{\prime \prime} \mathrm{E}$ & KY364246 & KY393268 & KY393280 \\
\hline & SFC20150812-48 & Jongno-gu, Seoul & $37^{\circ} 34^{\prime} 28.30^{\prime \prime} \mathrm{N} / 126^{\circ} 59^{\prime} 44.28^{\prime \prime} \mathrm{E}$ & KY364247 & & KY393281 \\
\hline & SFC20150918-07 & Jongno-gu, Seoul & $37^{\circ} 34^{\prime} 26.70^{\prime \prime} \mathrm{N} / 126^{\circ} 59^{\prime} 36.12^{\prime \prime} \mathrm{E}$ & KY364248 & KY393269 & KY393282 \\
\hline & SFC20160315-03 & Yangyang-gun, Gangwon-do & $38^{\circ} 07^{\prime} 17.46^{\prime \prime} \mathrm{N} / 128^{\circ} 33^{\prime} 06.78^{\prime \prime} \mathrm{E}$ & KY364249 & & KY393283 \\
\hline & SFC20160420-01 & $-a^{a}$ & & KY364250 & & \\
\hline \multirow[t]{4}{*}{ G. cf. adspersum } & SFC20141001-16 & Inje-gun, Gangwon-do & $37^{\circ} 57^{\prime} 11.80^{\prime \prime} \mathrm{N} / 128^{\circ} 19^{\prime} 24.52^{\prime \prime} \mathrm{E}$ & KY364251 & KY393270 & KY393284 \\
\hline & SFC20141001-22 & Inje-gun, Gangwon-do & $37^{\circ} 57^{\prime} 02.55^{\prime \prime} \mathrm{N} / 128^{\circ} 19^{\prime} 29.46^{\prime \prime} \mathrm{E}$ & KY364252 & KY393271 & KY393285 \\
\hline & SFC20140701-31 & Inje-gun, Gangwon-do & $37^{\circ} 56^{\prime} 50.06^{\prime \prime} \mathrm{N} / 128^{\circ} 19^{\prime} 47.85^{\prime \prime} \mathrm{E}$ & KY364253 & & \\
\hline & SFC20160115-20 & Yangpyeong-gun, Gyeonggi-do & $37^{\circ} 29^{\prime} 20.09^{\prime \prime} \mathrm{N} / 127^{\circ} 36^{\prime} 34.14^{\prime \prime} \mathrm{E}$ & KY364254 & KY393272 & KY393286 \\
\hline \multirow[t]{4}{*}{ G. cf. applanatum } & SFC20141001-24 & Inje-gun, Gangwon-do & $37^{\circ} 56^{\prime} 46.46^{\prime \prime} \mathrm{N} / 128^{\circ} 20^{\prime} 00.98^{\prime \prime} \mathrm{E}$ & KY364255 & KY393273 & KY393287 \\
\hline & SFC20141001-25 & Inje-gun, Gangwon-do & $37^{\circ} 57^{\prime} 13.39^{\prime \prime} \mathrm{N} / 128^{\circ} 19^{\prime} 16.80^{\prime \prime} \mathrm{E}$ & KY364256 & & \\
\hline & SFC20141012-02 & Inje-gun, Gangwon-do & $37^{\circ} 57^{\prime} 12.84^{\prime \prime} \mathrm{N} / 128^{\circ} 19^{\prime} 18.18^{\prime \prime} \mathrm{E}$ & KY364257 & & \\
\hline & SFC20150930-02 & Inje-gun, Gangwon-do & $38^{\circ} 07^{\prime} 30.12^{\prime \prime} \mathrm{N} / 128^{\circ} 12^{\prime} 10.08^{\prime \prime} \mathrm{E}$ & KY364258 & KY393274 & KY393288 \\
\hline \multirow[t]{13}{*}{ G. cf. gibbosum } & SFC20130404-21 & Sangju-si, Gyeongsangbuk-do & $36^{\circ} 31^{\prime} 47.93^{\prime \prime} \mathrm{N} / 128^{\circ} 04^{\prime} 27.06^{\prime \prime} \mathrm{E}$ & KY364259 & & \\
\hline & SFC20140702-12 & Seogwipo-si, Jeju-do & $33^{\circ} 14^{\prime} 54.58^{\prime \prime} \mathrm{N} / 126^{\circ} 21^{\prime} 03.42^{\prime \prime} \mathrm{E}$ & KY364260 & KY393275 & \\
\hline & SFC20140703-17 & Jeju-si, Jeju-do & $33^{\circ} 26^{\prime} 24.63^{\prime \prime} \mathrm{N} / 126^{\circ} 37^{\prime} 39.49^{\prime \prime} \mathrm{E}$ & KY364261 & & \\
\hline & SFC20150418-05 & Gwanak-gu, Seoul & $37^{\circ} 27^{\prime} 21.15^{\prime \prime} \mathrm{N} / 126^{\circ} 56^{\prime} 57.18^{\prime \prime} \mathrm{E}$ & KY364262 & & \\
\hline & SFC20150612-11 & Donghae-si, Gangwon-do & $37^{\circ} 27^{\prime} 51.09^{\prime \prime} \mathrm{N} / 129^{\circ} 01^{\prime} 00.16^{\prime \prime} \mathrm{E}$ & KY364263 & & \\
\hline & SFC20150630-23 & Jongno-gu, Seoul & $37^{\circ} 34^{\prime} 24.07^{\prime \prime} \mathrm{N} / 126^{\circ} 59^{\prime} 36.17^{\prime \prime} \mathrm{E}$ & KY364264 & KY393276 & KY393289 \\
\hline & SFC20150701-06 & Jeju-si, Jeju-do & $33^{\circ} 19^{\prime} 31.62^{\prime \prime} \mathrm{N} / 126^{\circ} 16^{\prime} 50.62^{\prime \prime} \mathrm{E}$ & KY364265 & & \\
\hline & SFC20150723-01 & Jongno-gu, Seoul & $37^{\circ} 34^{\prime} 22.66^{\prime \prime} \mathrm{N} / 126^{\circ} 59^{\prime} 37.49^{\prime \prime} \mathrm{E}$ & KY364266 & & \\
\hline & SFC20150812-02 & Jongno-gu, Seoul & $37^{\circ} 34^{\prime} 21.62^{\prime \prime} \mathrm{N} / 126^{\circ} 59^{\prime} 38.18^{\prime \prime} \mathrm{E}$ & KY364267 & & \\
\hline & SFC20150812-35 & Jongno-gu, Seoul & $37^{\circ} 34^{\prime} 20.40^{\prime \prime} \mathrm{N} / 126^{\circ} 59^{\prime} 45.21^{\prime \prime} \mathrm{E}$ & KY364268 & & \\
\hline & SFC20150812-36 & Jongno-gu, Seoul & $37^{\circ} 34^{\prime} 27.81^{\prime \prime} \mathrm{N} / 126^{\circ} 59^{\prime} 44.59^{\prime \prime} \mathrm{E}$ & KY364269 & & \\
\hline & SFC20150918-03 & Jongno-gu, Seoul & $37^{\circ} 34^{\prime} 24.63^{\prime \prime} \mathrm{N} / 126^{\circ} 59^{\prime} 39.11^{\prime \prime} \mathrm{E}$ & KY364270 & KY393277 & KY393290 \\
\hline & SFC20150918-08 & Jongno-gu, Seoul & $37^{\circ} 34^{\prime} 20.23^{\prime \prime} \mathrm{N} / 126^{\circ} 59^{\prime} 44.05^{\prime \prime} \mathrm{E}$ & KY364271 & KY393278 & KY393291 \\
\hline
\end{tabular}


